\title{
Laparoscopic Hiatal Hernia Repair with or without Fundoplication. Is There Any Difference?
}

\author{
Abdelrahman Mohamed Amin Sarhan, Muhammad Ali Baghdadi, Mohammed Mahmoud Mokhtar \\ Mohammed, Anas Abdelhmed Yousef Abdelhmed*. \\ Department of General Surgery, Zagazig University hospitals, Zagazig, Egypt. \\ *Correspondence to: Anas Abdelhmed Yousef Abdelhmed, E-mail: priority1953@gmail.com
}

\begin{abstract}
Background: A hiatal hernia is a type of hernia in which abdominal organs (typically the stomach) slip through the diaphragm into the middle compartment of the chest. This may result in gastroesophageal reflux disease (GERD) or laryngopharyngeal reflux (LPR) with symptoms such as a taste of acid in the back of the mouth or heartburn. Other symptoms may include swallowing trouble and chest pains.

Objectives: This study aimed to compare laparoscopic hiatal hernia repair (HHR) cruroplasty (the effect of hernia reduction and only repair of diaphragmatic crura) versus HHR with concomitant fundoplication in terms of relative frequency and severity of symptoms before laparoscopic antireflux surgery, and DeMeester scores (DMS), relative symptom improvement, patients' satisfaction, and complications after antireflux surgery.

Patients and methods: This prospective randomized study was conducted in GIT Unit of General Surgery Department, Faculty of Medicine, Zagazig University, on 18 patients with hiatal hernia underwent laparoscopic hiatal hernia repair. They were divided into two equal groups; 1st group was laparoscopic hiatal hernia repair (HHR) without fundoplication and 2nd group was with Nissen Fundoplication (HHR - LNF).

Results: We found that there was complete absence of hernia among HHE-LNF group $(0.0 \%)$ versus 2 patients $(22.2$ $\%)$ had persistent hernia after HHR group with no significance difference between both groups pre- and postoperatively. There was not a statistically significance difference between the two studied groups regarding success rate with $100.0 \%$ versus $77.8 \%$ among HHR_LNF and HHR respectively.

Conclusion: Laparoscopic hiatal hernia repair with Nissen Fundoplication had better short-term outcome than without Nissen fundoplication.
\end{abstract}

Keywords: Hiatal hernia, Gastroesophageal reflux disease, Laryngopharyngeal reflux.

\section{INTRODUCTION}

Hiatal hernia is a common disorder. It is characterized by a protrusion of any abdominal structure other than the esophagus into the thoracic cavity through a widening of the hiatus of the diaphragm ${ }^{(\mathbf{1})}$. Greater than $95 \%$ of hiatal hernias are Type I. Types II - IV hernias as a group are referred to as paraesophageal hernias (PEH), and are differentiated from Type I hernias by relative preservation of posterolateral phrenoesophageal attachments around the gastro-esophageal junction. Of the paraesophageal hernias, more than $90 \%$ are Type III, and the least common is Type $\mathrm{II}^{(2)}$.

The history of antireflux surgery over the last 48 years has shown that reduction of the hiatal hernia in conjunction with diaphragmatic crural approximation is at best a transient antireflux deterrent and that an additional procedure needs to be performed ${ }^{(3)}$.

Ultimately, a fundoplication is performed either through the chest (Belsey Mark IV) or through the abdomen involving varying degrees of encirclement of the distal esophagus by the fundoplication. Laparoscopic hiatal hernia repair (HHR) has been shown to provide good short- and long-term results in gastroesophageal reflux disease (GERD) ${ }^{(4)}$ and may reduce the laparoscopic antireflux surgery complications ${ }^{(5)}$. Fundoplication is also an important component of laparoscopic antireflux surgery performed for medication-refractory GERD ${ }^{(6)}$.

In addition, fundoplication is thought to support the anchoring of the cardia below the diaphragm, thereby reducing the risk of recurrence. For all these reasons, routine addition of fundoplication is commonly recommended ${ }^{(7)}$. Even more important, there is a risk of fundoplication-related complications and side effects. The frequency of gas-bloating symptoms after fundoplication are reported to be up to $58 \%$, and in about $20 \%$ of patients, new symptoms occur postoperatively. Therefore, intended improvement of GERD represents a trade-off against the risk of fundoplication related side effects ${ }^{(\mathbf{8})}$.

The question arises as to whether routine addition of a fundoplication is reasonable. Therefore, the aim of this study is to compare laparoscopic HHR (the effect of hernia reduction and only repair of diaphragmatic crura) with HHR with concomitant fundoplication in terms of relative frequency and severity of symptoms before laparoscopic antireflux surgery, and DeMeester scores (DMS), relative symptom improvement, patients' satisfaction and complications after antireflux surgery.

\section{PATIENTS AND METHODS}

This prospective randomized study was conducted in GIT Unit of General Surgery Department, Faculty of 
Medicine, Zagazig University during the period from

February to July 2021. The study included 18 patients with hiatal hernia underwent laparoscopic hiatal hernia repair. They were divided into two equal groups; $1^{\text {st }}$ group was laparoscopic hiatal hernia repair (HHR) without fundoplication and $2^{\text {nd }}$ group was with Nissen Fundoplication (HHR - LNF).

\section{Ethical consent:}

An approval of the study was obtained from Zagazig University Academic and Ethical Committee. Every patient signed an informed written consent for acceptance of the operation. This work has been carried out in accordance with The Code of Ethics of the World Medical Association (Declaration of Helsinki) for studies involving humans.

Inclusion criteria: Age above 18 years. Residual symptoms while on medical therapy or endoscopic esophagitis after at least three months of intensive acid suppression therapy, or both. Dependence on continuous medication and expenses. Pathological 24-h esophageal $\mathrm{pH}$ monitoring in symptomatic patients without preoperative endoscopic signs of erosive esophagitis.

Exclusion criteria: Pregnancy. Patient not fit for surgery. Patients with central nervous system diseases or connective tissue diseases. Patients with previous esophageal or gastric surgery. Presence of esophageal stricture, and shortened esophagus. Patients with Barrett's esophagus. Patients has para-esophageal hernia.

All patients were subjected to full history taking, routine clinical examination and laboratory investigations including complete blood count, tests for liver function, kidney function, random sugar and blood fluidity. Radiological evaluation, endoscopic evaluation and computed tomography if possiblej

\section{Pre-operative assessment:}

Preoperatively, the patients were investigated for the type of hiatal hernia with an upper-gastrointestinal endoscopy. The patients were screened for evidence of gastroesophageal reflux disease (GERD) as confirmed by upper-gastrointestinal endoscopy, by symptomatic voluminous reflux and by a positive proton pump inhibitor test. If apparent esophagitis were graded according to the Savary and Miller or Los Angeles classification (9). Pathological 24-h esophageal $\mathrm{pH}$ monitoring in symptomatic patients without preoperative endoscopic signs of erosive esophagitis.

\section{Operative technique:}

In laparoscopic hiatal hernia repair without fundoplication all procedures were performed as described by Muller-Stich et al. ${ }^{(10)}$ incision of the lesser omentum and the peritoneum at the hiatus and the hernia sac was completely removed. Bougie was used to identify the esophagus, a 32 Fr esophageal. After complete mobilization of the hernia and the distal esophagus, the hiatus was narrowed with two to three non-absorbable, multifilament sutures. Finally, an anterior cardiophrenicopexy was routinely added with 5-7 non-absorbable, monofilament sutures.

In laparoscopic hiatal hernia repair with fundoplication: The surgical technique of laparoscopic surgical procedure was performed as described by Zhang et $\mathbf{a l} .{ }^{(11)}$. The patient was sedated and placed in a reverse-trendelenburg position, with the lower extremities abducted. The operating surgeon was standing between the legs of the patient, with the first assistant on the left side of the patient and the second assistant on the right side of the surgeon. A veress needle was inserted close to the rib cage, and a pneumoperitoneum was created. The primary $10-\mathrm{mm}$ trocar was inserted at the upper edge of the navel. Four more trocars will be then inserted in the upper abdomen under direct visualization. The liver was retracted, and the esophageal hiatus was exposed. The stomach was repositioned, and A 3-4 cm of esophageal reposition was dissected intra-abdominally. The diaphragmatic crura was exposed, and sutured 2-3 times intermittently with non-absorbable sutures_to reduce the esophageal hiatus. If 360-degree Nissen fundoplication is added. A full-circle valve was formed from the posterior and anterior aspects of the fundus and sutured together using three separate nonabsorbable $2-0$ sutures.

\section{Follow-up assessment:}

An objective follow-up (upper-gastrointestinal endoscopy) was done. All patients received a standardized questionnaire (symptomatic follow-up). All the questions focused on the time before the operation as well as the state at the time of the survey. The questionnaire included questions on reflux symptoms, such as heartburn and regurgitation, as well as side effects, such as dysphagia and gas bloating. The patients could rate their symptoms as none $=0$, mild $=$ 1 , moderate $=2$ and severe $=3$. Included questions on the surgical success and the patients' physical state. Finally, the patients were asked how satisfied they are with their surgical results and whether they would be willing to undergo the operation again.

\section{Statistical analysis}

Data collected throughout history, basic clinical examination, laboratory investigations and outcome measures were coded, entered and analyzed using Microsoft Excel software. Data were then imported into Statistical Package for the Social Sciences (SPSS version 20.0) software for analysis. According to the type of data, qualitative data were represented as number and percentage, while quantitative continues group was represented by mean $\pm \mathrm{SD}$. The following tests were used to test differences for significance; difference and association of qualitative variable by $\mathrm{Chi}$ square test $\left(\mathrm{X}^{2}\right)$. Differences between quantitative independent multiple by ANOVA, correlation by Pearson's correlation. $\mathrm{P}$ value $\leq 0.05$ was considered significant. 
RESULTS

Table (1): Comparison between the two studied groups regarding socio-demographic characteristics.

\begin{tabular}{|c|c|c|c|c|}
\hline Variables & $\begin{array}{c}\text { HHR } \\
\text { No }=9\end{array}$ & $\begin{array}{c}\text { HHR with } \\
\text { Fundoplication } \\
\text { No }=9\end{array}$ & Test & $P_{\text {P Value }}$ \\
\hline $\begin{array}{l}\text { Age (years) } \\
\text { Mean } \pm \text { SD } \\
\text { Range }\end{array}$ & $\begin{array}{c}46.2 \pm 10.5 \\
(30-60)\end{array}$ & $\begin{array}{c}49.1 \pm 9.7 \\
(28-61)\end{array}$ & $\mathrm{M} . \mathrm{W}=0.6$ & 0.8 \\
\hline BMI $\left(\mathbf{K g} / \mathbf{m}^{2}\right)-$ Mean \pm SD & $24.1 \pm 1.9$ & $23.9 \pm 1.8$ & M.W $=0.2$ & 0.9 \\
\hline $\begin{array}{l}\text { Sex } \\
\text { Male (8) } \\
\text { Female (10) }\end{array}$ & $\begin{array}{l}3(33.3 \%) \\
6(66.7 \%)\end{array}$ & $\begin{array}{l}5(55.6 \%) \\
4(44.4 \%)\end{array}$ & $X^{2}=0.9$ & 0.3 \\
\hline
\end{tabular}

Table (1) showed that there was no statistically significance difference between the two studied groups regarding age, sex and BMI.

Table (2): Comparing operative data between the two studied groups

\begin{tabular}{|l|c|c|c|c|}
\hline \multicolumn{1}{|c|}{ Variables } & $\begin{array}{c}\text { HHR } \\
\text { No=9 }\end{array}$ & $\begin{array}{c}\text { HHR-LNF } \\
\text { No=9 }\end{array}$ & M.W & P_Value \\
\hline \hline $\begin{array}{l}\text { Operative time (minutes) } \\
\text { Mean } \pm \text { SD }\end{array}$ & $105.7 \pm 15.6$ & $129.4 \pm 17.3$ & 3.9 & $\mathbf{0 . 0 0 7}^{*}$ \\
\hline $\begin{array}{l}\text { Post-Operative hospital stay (days) } \\
\text { Mean } \pm \text { SD }\end{array}$ & $5.1 \pm 0.9$ & $5.8 \pm 1.5$ & 1.2 & 0.3 \\
\hline $\begin{array}{l}\text { Immediate post-Operative complications } \\
\text { - No }\end{array}$ & $\begin{array}{r}7(77.8 \%) \\
1(11.1 \%) \\
\text {-Transient S.C emphysema in the neck } \\
\text { - Pleural effusion }\end{array}$ & $\begin{array}{c}7(77.8 \%) \\
2(22.2 \%) \\
0(0.0 \%)\end{array}$ & 1.3 & 0.5 \\
\hline
\end{tabular}

* Statistically significant difference $(\mathrm{P}<0.05)$

Table (2) showed that there was statistically significant higher operative time among HHR-LNF group than in HHR group. Post-operative hospital stay and immediate post-operative complications showed non-significant difference between both groups as there were 2 patients $(22.2 \%)$ versus one patient $(11.1 \%)$ among HHR- LNF and HHR respectively had transient subcutaneous emphysema in the neck. This emphysema resolved completely within one to two weeks and only one patient $(11.1 \%)$ among HHE group had pleural effusion, which was absorbed within one week.

Table (3): Comparing post-operative outcomes between the two groups

\begin{tabular}{|l|c|c|c|c|}
\hline \multicolumn{1}{|c|}{ Variables } & $\begin{array}{c}\text { HHR } \\
\text { No=9 }\end{array}$ & $\begin{array}{c}\text { HHR- LNF } \\
\text { No=9 }\end{array}$ & M.W & P_Value \\
\hline \hline No. of reflux episode( Mean \pm SD) & $31.7 \pm 14.5$ & $18.5 \pm 10.3$ & 2.2 & $\mathbf{0 . 0 0 4}^{*}$ \\
\hline $\begin{array}{l}\text { No. of lasting 5 minutes reflux } \\
\text { Mean } \pm \text { SD }\end{array}$ & $23 \pm 1.1$ & $0.3 \pm 0.02$ & 5.4 & $\mathbf{0 . 0 0 1}^{* *}$ \\
\hline $\begin{array}{l}\text { Resting LOS pressure (mm Hg) } \\
\text { Mean } \pm \text { SD }\end{array}$ & $14.2 \pm 7.8$ & $20.5 \pm 3.9$ & 2.1 & $\mathbf{0 . 0 3}^{*}$ \\
\hline $\begin{array}{l}\text { Time PH < 4 (minutes) } \\
\text { Mean } \pm \text { SD }\end{array}$ & $97.3 \pm 45.1$ & $42.3 \pm 24.9$ & 3.2 & $\mathbf{0 . 0 0 1}^{* *}$ \\
\hline Demeester score (Mean \pm SD) & $13.5 \pm 4.7$ & $6.9 \pm 4.1$ & 4.3 & $\mathbf{0 . 0 0 1}^{* *}$ \\
\hline
\end{tabular}

M.W = Mann - Witenny U. test $\quad *$ statistically significant difference $(\mathrm{P}<0.05)$. ** statistically highly significant difference $(\mathrm{P}<0.001)$

Table (3) showed that there was statistically highly significant improvement (decreased) of DeMeester score, number of reflux episodes, number of lasting 5 minutes reflux episodes and time of $\mathrm{PH}<4$. Moreover, there was statistically significant improvement on resting LOS pressure with more improvement among HHR_LNF. 
Table (4): Surgical success between the two studied groups

\begin{tabular}{|c|c|c|c|}
\hline \multirow{2}{*}{ Surgical success } & $\begin{array}{c}\text { HHR } \\
\text { No=9(\%) }\end{array}$ & $\begin{array}{c}\text { HHR_LNF } \\
\text { No=9 }(\%)\end{array}$ & P_Value \\
\hline \hline Success & $\begin{array}{c}7(77.8 \%) \\
2(22.2 \%)\end{array}$ & $\begin{array}{c}9(100.0 \%) \\
0(0.0 \%)\end{array}$ & 0.1 \\
Failure & . & & \\
\hline
\end{tabular}

Table (4) showed that there was no statistically significance difference between the two studied groups regarding success rate with $100.0 \%$ versus $77.8 \%$ between HHR_LNF and HHR respectively.

Table (5): Comparing failure of reflux treatment between the two studied groups

\begin{tabular}{|l|c|c|c||}
\hline \multicolumn{1}{|c|}{ Variables } & $\begin{array}{c}\text { HHR } \\
\text { No=9 }(\%)\end{array}$ & $\begin{array}{c}\text { HHR-LNF } \\
\text { No=9(\%) }\end{array}$ & P_Value \\
\hline \hline Moderate or Severe heart burn & $3(33.3 \%)$ & $1(11.1 \%)$ & 0.2 \\
\hline Moderate or severe regurgitation & $2(22.2 \%)$ & $1(11.1 \%)$ & 0.5 \\
\hline esophagitis at least grade B & $1(11.1 \%)$ & $0(0.0 \%)$ & 0.3 \\
\hline Requirement of daily PPI III & $1(11.1 \%)$ & $0(0.0 \%)$ & 0.3 \\
\hline Need for operation for GERD & $0(0.0 \%)$ & $0(0.0 \%)$ & 1 \\
\hline $\begin{array}{l}\text { Total No. of patients fulfilling at least two } \\
\text { criteria }\end{array}$ & $2(22.2 \%)$ & $0(0.0 \%)$ & 0.1 \\
\hline
\end{tabular}

Table (5) showed that there was less failure of reflex treatment among HHR-LNF group than HHR but with no statistically significance difference between of reflux treatment.

Table (6): Long-term post-operative complications between the two studied groups

\begin{tabular}{|l|c|c|c|c|}
\hline \multirow{2}{*}{ Variables } & $\begin{array}{c}\text { HHR } \\
\text { No=9 }(\%)\end{array}$ & $\begin{array}{c}\text { HHR-LNF } \\
\text { No=9(\%) }\end{array}$ & \multirow{2}{*}{ P_Value } \\
\cline { 1 - 4 } & $1(11.1 \%)$ & $2(22.2 \%)$ & & 0.5 \\
\hline \hline Dysphagia & $3(33.3 \%)$ & $1(11.1 \%)$ & & 0.2 \\
\hline Abdominal pain & & & \\
\hline
\end{tabular}

Table (6) showed that there was no statistically significance difference between HHR and HHR-LNF groups regarding post-operative complications.

Table (7): Comparing modified visick score between the two studied groups

\begin{tabular}{|l|c|c|c|}
\hline \multicolumn{1}{|c|}{ Modified visick score } & $\begin{array}{c}\text { HHR } \\
\text { No=9(\%) }\end{array}$ & $\begin{array}{c}\text { HHR-LNF } \\
\text { No=9(\%) }\end{array}$ & P_Value \\
\hline \hline I (No symptoms ) & $5(55.6 \%)$ & $7(77.8 \%)$ & 0.3 \\
\hline II (Mild symptom & $2(22.2 \%)$ & $2(22.2 \%)$ & 1 \\
\hline III significant symptom & $2(22.2 \%)$ & $0(0.0 \%)$ & 0.1 \\
\hline IV symptom as bad or worser & $0(0.0 \%)$ & $0(0.0 \%)$ & 1 \\
\hline
\end{tabular}

Table (7) showed that there was higher improvement on modified visick score among HHR- LNF than in HHR $(77.8 \%)$ versus $(55.6 \%)$ but this difference was not statistically significant. 
Table (8): Comparing total patients' outcomes between the two studied groups

\begin{tabular}{|c|c|c|c|}
\hline Variables & $\begin{array}{c}\text { HHR } \\
\text { No }=9(\%)\end{array}$ & $\begin{array}{l}\text { HHR-LNF } \\
\text { No }=9(\%)\end{array}$ & $P_{-}$Value \\
\hline $\begin{array}{l}\text { Surgical result } \\
\text { - Excellent } \\
\text { - Good } \\
\text { - Poor } \\
\end{array}$ & $\begin{array}{l}5(55.6 \%) \\
4(44.4 \%) \\
0(0.0 \%)\end{array}$ & $\begin{array}{c}7(77.8 \%) \\
2(22.2 \%) \\
0(0.0 \%)\end{array}$ & 0.3 \\
\hline $\begin{array}{l}\text { Physical state } \\
\text { - Normalized } \\
\text { - Improved } \\
\text { - Unsatisfied } \\
\end{array}$ & $\begin{array}{l}5(55.6 \%) \\
3(33.3 \%) \\
1(11.1 \%)\end{array}$ & $\begin{array}{c}7(77.8 \%) \\
2(22.2 \%) \\
0(0.0 \%) \\
\end{array}$ & 0.4 \\
\hline $\begin{array}{l}\text { Patients satisfaction } \\
\text { - Very satisfied } \\
\text { - Satisfied } \\
\text { - Unsatisfied } \\
\end{array}$ & $\begin{array}{l}5(55.6 \%) \\
2(22.2 \%) \\
2(22.2 \%)\end{array}$ & $\begin{array}{c}7(77.8 \%) \\
2(22.2 \%) \\
0(0.0 \%)\end{array}$ & 0.3 \\
\hline
\end{tabular}

Table (8) showed that there was more excellent surgical results, higher normalized physical state and more very satisfied patients $(77.8 \%)$ versus $(55.6 \%)$ among HHR-LNF than in HHR groups with no statistically significance difference.

\section{DISCUSSION}

We found that there was no statistically significant difference between the two studied groups regarding age, sex, and BMI. In contrast to our findings, Samuel and Nabe ${ }^{(\mathbf{1 2})}$ conducted a study that revealed that higher body mass index above $30 \mathrm{Kg} / \mathrm{m}^{2}$ has a negative association with silding hiatus hernia while the risk seems higher in women and those with BMI indicating overweight ${ }^{(\mathbf{1 2})}$.

Our findings cleared that there was statistically significant longer operative time among HHR-LNF group than HHR group. Regarding post-operative hospital stay and immediate post-operative complications, there was non-significant difference between both groups. This because there were 2 patients $(22.2 \%)$ versus one patient $(11.1 \%)$ among HHR- LNF and HHR respectively had transient subcutaneous emphysema in the neck which resolved completely within one to two weeks. In addition, there was one patient $(11.1 \%)$ among HHE group had pleural effusion which absorbed within one week.

We also found that there was statistically highly significant improvement (decreased) of DeMeester score, number of reflux episodes, number of lasting 5 minutes reflux episodes and time of $\mathrm{PH}<4$. Additionally, there was statistically significant improvement in resting LOS pressure with more improvement among HHR_LNF. There was a highly statistically significant post-operative improvement of esophagitis on both groups with no difference between the two groups pre- nor post-operatively. In the same line with us, Furnée and colleagues ${ }^{(13)}$ conducted a prospective study, which showed that normalization of esophageal acid exposure was seen in $61 \%$ of patients who had a fundoplication. They also found that symptomatic outcome was successful in almost $90 \%$ of patients who underwent laparoscopic large sliding hiatal hernia repair ${ }^{(\mathbf{1 3})}$. These results are in contrast to the outcome of surgery for gastroesophageal reflux disease carried out in patients with normal gastroesophageal anatomy, or type I hiatal hernias. In the study of Draaisma and colleagues ${ }^{(14)}$ reported that persistent abnormal acid exposure was shown in $4.1-12.5 \%$ of patients.

There was no statistically significance difference between the two studied groups regarding success rate with $100.0 \%$ versus $77.8 \%$ between HHR_LNF and HHR respectively. On the other side, the results of Furnée and colleagues (13) revealed a success percentage of ninety percent of patients who underwent laparoscopic large sliding hiatal hernia repair, regardless of the addition or omission of an antireflux fundoplication.

This study showed that there was also less failure of reflux treatment among HHR-LNF group than in HHR group but with no statistically significant difference between them. There was no statistically significance difference between HHR and HHR-LNF groups regarding past-operative complications. There was higher improvement on modified visick score among HHR-LNF than in HHR (77.8 \%) versus $(55.6 \%)$ but this difference was not statistically significant. There was more excellent surgical results, higher normalized physical state, and more very satisfied patients $(77.8 \%)$ versus $(55.6 \%)$ among HHR-LNF than in HHR groups with no statistically significance difference.

Apparently, in patients with a large sliding hiatal hernia, other mechanisms contribute to gastroesophageal reflux. The more prominent anatomical disturbances that require more extensive dissection, thereby destroying anatomical structures, 
which contribute to the natural antireflux mechanism, like the phrenoesophageal membrane and preaortic fascia, have previously been reported as the possible cause $^{(15)}$. However, these structures are also dissected during an antireflux fundoplication primarily performed for gastroesophageal reflux disease. Compared to primary antireflux surgery, more extensive dissection of the esophageal and gastric wall is required during large sliding hiatal hernia repair. This may impair the intrinsic antireflux barrier at the gastroesophageal junction and explain the less favorable objective outcome in these patients ${ }^{(16)}$. In addition, Aly and colleagues (17) found that the suboptimal anatomical status after laparoscopic hiatal hernia repair (i.e. recurrent hiatal herniation) was present in a substantial number of patients (19\%), as was reported previously. This may also contribute to the less than expected functional outcome after large sliding hiatal hernia repair.

\section{CONCLUSION}

We concluded that laparoscopic hiatal hernia repair with Nissen fundoplication has better short-term outcome than without Nissen fundoplication. This concept may share in reducing the postoperative complications and improve the surgical outcome. We recommend the implementation of the laparoscopic hiatal hernia repair with Nissen fundoplication rather than without Nissen fundoplication. In addition, further studies must be done to analyze the clinical outcomes in patients postoperatively.

\section{Financial support and sponsorship: Nil.}

Conflict of interest: Nil.

\section{REFERENCES:}

1. Felix V, Yogi I, Senday D et al. (2019): Post-operative giant hiatal hernia: A single center experience. Medicine, 98 (23): 15834-38.

2. Sihag S, Rattner D (2016): Management of complicated and strangulated hiatal hernias. In Acute care surgery handbook. Springer, Cham, Pp: 65-90.

3. Fernando A, Herbella A, Cristina $\mathrm{C}$ et al. (2017): History of medical and surgical antireflux therapy, ACC, Amaral failed antireflux therapy. Springer Link, 172: 638. https://link.springer.com/book/10.1007/9783-319-46885-3

4. Astit E, Lovece A, Bonavina $L$ et al. (2016): Laparascopic management of large hiatus hernia fiveyears cohert study and comparison of mesh-augmented versus standerized crura repair. Surg Endosc., 30: 3544.

5. Sasaki A, Obuchi T, Nakajima J et al. (2010): Laparascopic Heller myotomy with Dor fundoplication for achalasia: long-term outcomes and effect on chest pain. Dis Esophagus, 23: 284-289.

6. Wilshire C, Watson T (2013): Surgical management of gastroesophageal reflux disease. Gastroenterology Clinics of North America, 42: 119-131.

7. Müller-Stich B, Achtstätter V, Diener $\mathrm{M}$ et al. (2015): Repair of paraesophageal hiatal hernias-is a fundoplication needed? a randomized controlled pilot trial. Journal of the American College of Surgeons, 221 (2): 602-610.

8. Witteman B, Conchillo J, Rinsma $\mathbf{N}$ et al. (2015): Randomized controlled trial of transoral incisionless fundoplication vs. proton pump inhibitors for treatment of gastroesophageal reflux disease. American Journal of Gastroenterology, 110 (4): 531-542.

9. Lundell L, Dent J, Bennett J et al. (1999): Endoscopic assessment of oesophagitis: clinical and functional correlates and further validation of the Los Angeles classification. Gut, 45: 172-180.

10. Muller-Stich B, Linke G, Borovicka J et al. (2008): Laparoscopic mesh-augmented hiatoplasty as a treatment of gastroesophageal reflux disease and hiatal hernias-preliminary clinical and functional results of a prospective case series. Am J Surg., 195: 749-756.

11. Zhang C, Wang Z, Wu J et al. (2012): A preliminary investigation of laparoscopic fundoplication treatment on gastroesophageal reflux disease-related respiratory symptoms. Surg Laparosc Endosc Percutan Tech., 22: 406-409.

12. Samuel D, Nabe B (2018): Hiatus Hernia and Body Mass Index (BMI): A Possible Correlation?. American Journal of Medical Case Reports, 6 (4): 75-78.

13. Furnée E, Draaisma W, Gooszen H et al. (2011): Tailored or routine addition of an antireflux fundoplication in laparoscopic large hiatal hernia repair: a comparative cohort study. World Journal of Surgery, 35 (1): 78-84.

14. Draaisma W, Rijnhart-de Jong H, Broeders I et al. (2006): Five-year subjective and objective results of laparoscopic and conventional Nissen fundoplication: a randomized trial. Annals of Surgery, 244 (1): 34-38.

15. Roman S, Kahrilas P (2014): The diagnosis and management of hiatus hernia. BMJ., 349: 6154-58.

16. Sfara A, Dumitrascu D (2019): The management of hiatal hernia: an update on diagnosis and treatment. Medicine and Pharmacy Reports, 92 (4): 321-326.

17. Aly A, Munt J, Jamieson G et al. (2005): Laparoscopic repair of large hiatal hernias. Journal of British $\quad$ Surgery, $92 \quad$ (5): $648-653$. 